Primljen / Received: 4.10.2012. Ispravljen / Corrected: 16.1.2013. Prihvaćen / Accepted: 20.1.2013. Dostupno online / Available online: 15.2.2013.

\section{Patch loading - analytical approach to critical load determination}

Authors:

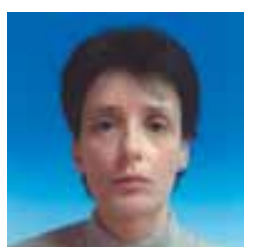

Olga Mijušković, Branislav Ćorić

Original scientific paper

\section{Patch loading - analytical approach to critical load determination}

The problem of plate stability under patch-loading can be analyzed using a variety of mathematical models by which the problem can be more or less realistically described. Models adopted in this paper serve as the basis for checking applicability of the analytical solution when subjected to complex load conditions. The accuracy of the procedure, proven by comparison with the data obtained through numerical models, and achieved by introduction of the exact stress function and use of appropriate deflection functions, confirms correctness of the solution presented in the paper.

Key words:

elastic stability of plates, exact stress function, mixed boundary conditions, patch loading

Izvorni znanstveni rad

\section{Olga Mijušković, Branislav Ćorić}

\section{Analitički postupak odredivanja kritičnog opterećenja - patch loading}

Prof. Branislav Ćorić, PhD. CE

University of Belgrad

Faculty of Civil Engineering

bcoric@grf.bg.ac.rs
Problem stabilnosti ploča pri djelovanju patch-loadinga može se analizirati primjenom različitih matematičkih modela koji ga, manje ili više, realno opisuju. Modeli usvojeni u ovom radu poslužili su kao osnova za provjeru ponašanja analitičkog rješenja u uvjetima djelovanja složenih opterećenja. Preciznost postupka, dokazana usporedbom s podacima dobivenim primjenom numeričkih metoda i ostvarena prije svega jer su uvedene točne funkcije naprezanja; te primijenjene odgovarajuće funkcije progiba, potvrdila je točnost izvedenog rješenja.

Ključne riječi:

elastična stabilnost ploča, točna funkcija naprezanja, kombinirani rubni uvjeti, patch-loading

Wissenschaftlicher Originalbeitrag

Olga Mijušković, Branislav Ćorić

\section{Analytisches Verfahren zur Bestimmung kritischer Belastungen - patch- loading}

IDas Stabilitätsproblem von Platten unter Belastungen in der Form von patch-loading kann durch die Anwendung verschiedener mathematischer Modelle analysiert werden, die das Problem mehr oder weniger wahrheitsgetreu darstellen. Die in der vorliegenden Arbeit angenommenen Modelle sind als Grundlage für die Untersuchung des Verhaltens der analytischen Lösung in Bezug auf kombinierte Belastungen eingesetzt worden. Die Genauigkeit des angewandten Verfahrens, die hauptsächlich durch die Einführung exakter Spannungsfunktionen und entsprechender Deformationsfunktionen erzielt werden konnte, ist durch den Vergleich mit auf numerischen Methoden beruhenden Resultaten erwiesen worden und bestätigt die Richtigkeit der dargestellten Lösung.

Schlüsselwörter:

elastische Plattenstabilität, exakte Spannungsfunktion, kombinierte Randbedingungen, patch-loading 


\section{Introduction}

In steel structures, buckling problem of the high steel girders under variable external loads is still very interesting topic. Presently available literature abounds with data regarding this problem, but mostly obtained by numerical or experimental methods. Analytical approach has been avoided mostly because of unknown stress distribution.

In the series of papers based on Mathieu's method [1] from 1890, Pavlovic, Baker and Tahan [2] and later Liu [3] and Mijuskovic [4] developed very precise approach for exact stress function determination for main case of rectangular plate under arbitrary external load. Existence of such solutions created the basis for the analysis of very complex stability problems in real steel structures.

Analytical approach to critical load determination based on exact stress functions implementation, is verified for relatively simple case of plate under (DEA) compression [3-5]. In this paper the next step is introduced through a significantly complicated problem of the plate under locally distributed stress (patch loading) applied on the upper flange of the steel girder. That way, the applicability and accuracy of introduced analytical approach can be proven on a more demanding and near to real life engineering problems.

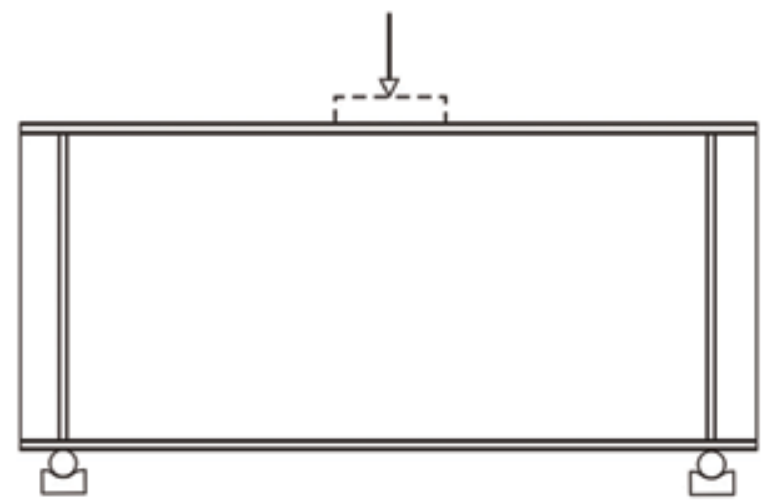

Figure 1. Model without transverse stiffeners

The case of patch loading can be analyzed by using different mathematical models which are describing the mentioned problem with different levels of accuracy. Considering models with different levels of complexity, it is possible to compare the results and analyze contribution of individual parameters to the value of the critical load.

In this paper, two basic mathematical models are chosen to represent buckling problems of plates under locally distributed compression. As shown in Figure 1.2, superposition of two fundamental load types (DEA and DEB) [1-5] is used to describe two initial models for the case of patch loading.

The next step would be raising model to a more complex level through introduction of the shear stresses along vertical stiffeners with task to equilibrate external loads (the third fundamental load SEB).The final goal would be defining and analyzing model with effects of shear stress at the flangeweb junction (load SOA) whose distribution depends on the rigidity of the flange. Until now, such effect has never been discussed.

a) Assumptions adopted for model 1

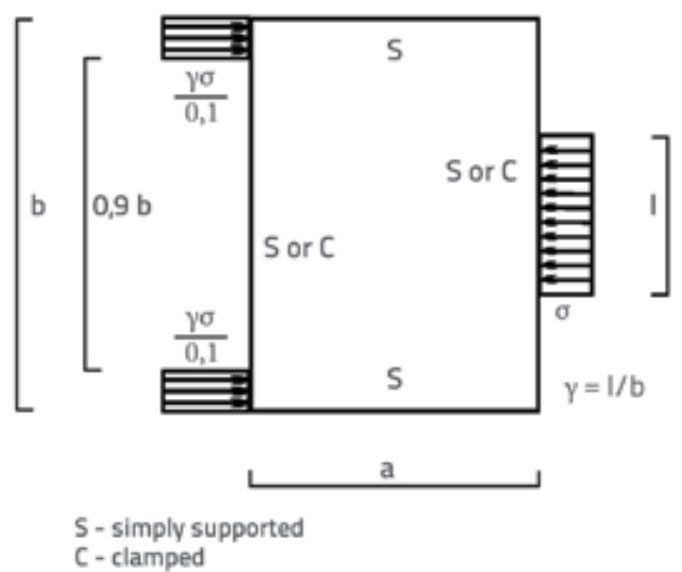

b) Assumptions adopted for model 2

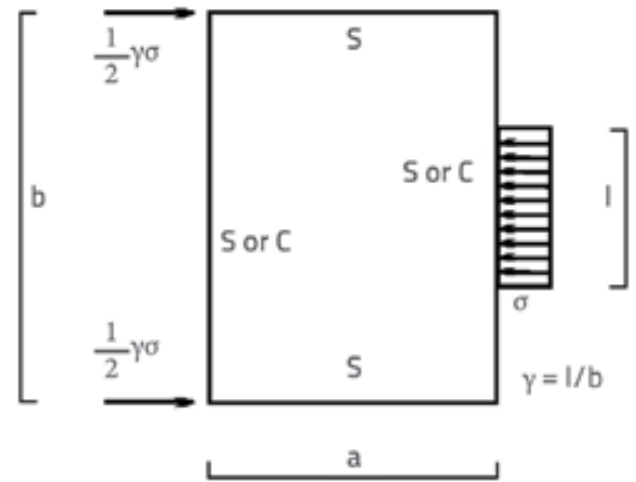

S - simply supported

C - uclamped

Figure 2. Basic models for patch-loading analysis

Comparative analysis of the four models defining stability problem of rectangular plates with different boundary conditions under patch loading, can point to interesting conclusions about the relevance of various parameters and their influence on the value of the critical load. 

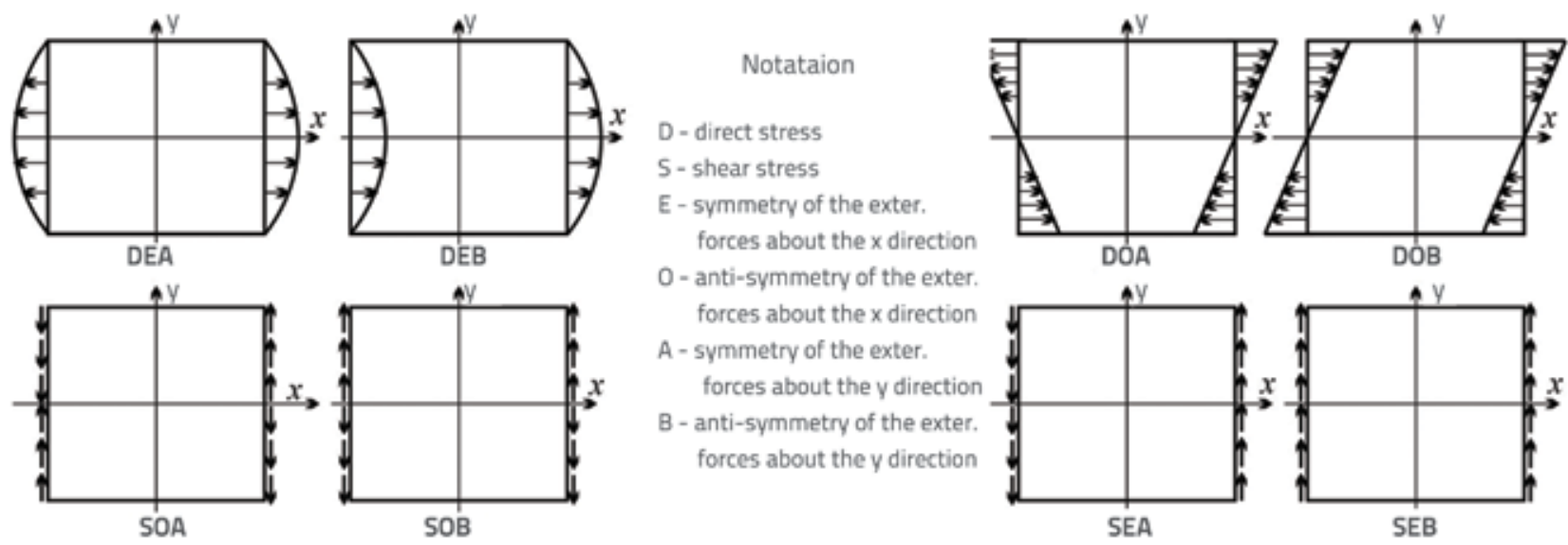

Figure 3. Eight basic load cases

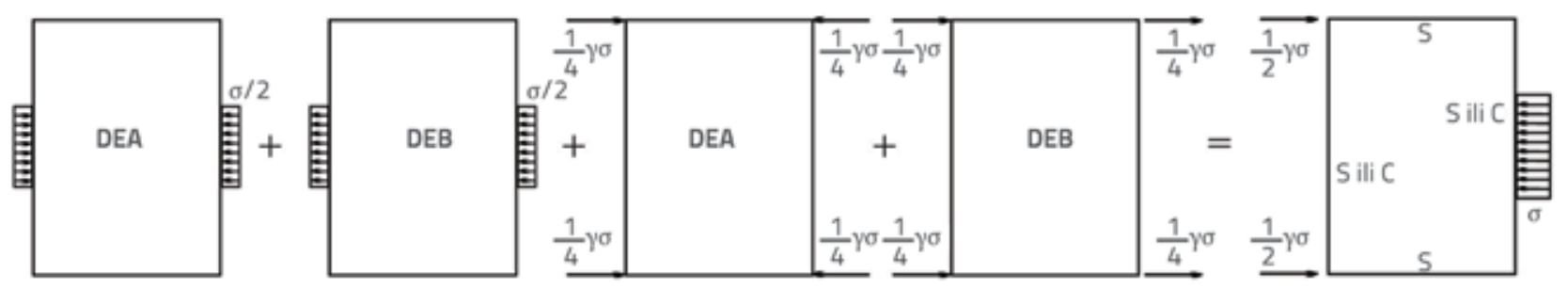

Figure 4. Creation of model 2 by combination of two basic load cases

\section{Basic outline}

Analytical approach to stability problems of the plates due to the patch-loading begins with determination of exact stress functions for selected models. In the previous paper [5] it has been already explained that any arbitrary load (normal and/or shear) which acts along the edges of the plate, can be described by the chosen functions (even and/or odd in relation to the coordinate axes), so the total solution is obtained by the adequate combination of eight basic cases (Figure 3.).

For the presented initial models, external load is obtained by combining symmetrical (DEA) and anty-symmetrical (DEB) basic types (Figure 3.). Since the results for stress functions for the DEA case can be found in literature [3-5], only DEB case is presented in this paper.

In the Figure 4 . the procedure for obtaining the exact stress distribution for the model 2 is explained by superposition of the adequate DEA and DEB solutions. The possibility to achieve exact stress functions for complex cases of plates under patch loading guarantees accurate analytical approach to critical load determination. So far, in the literature, only in the researches of Pavlovic and Liu $[3,6,7]$ it is possible to find analytical results for buckling loads, but exclusively for simply supported plates. Up to now, for this load case and the plates with different boundary conditions, there are no precise analytical solutions. In this paper, two mathematical models are used to prove accuracy of presented analytical approach. All the results in this paper are reaffirmed by numerical finite-element (ANSYS) runs.

\subsection{Mathieu's solution}

Although basic equations can be found in literature [1-5], before proceeding with solution it is necessary to summarize the main governing expressions of two-dimensional elasticity, since Mathieu's notation and approach (XIX century work) depart from current conventions. In his paper [1], Mathieu expressed the known equilibrium equations, without the presence of body forces, in terms of displacements:

$$
\begin{array}{lll}
\frac{\partial \sigma_{x}}{\partial x}+\frac{\partial \tau_{x y}}{\partial y}=0 & & \Delta u=-\frac{1}{\varepsilon} \frac{d v}{d x} \\
\frac{\partial \tau_{y x}}{\partial x}+\frac{\partial \sigma_{y}}{\partial y}=0 & \text { Mathieu } \Rightarrow & \Delta v=-\frac{1}{\varepsilon} \frac{d v}{d y}
\end{array}
$$

where:

$$
\begin{array}{ll}
\Delta & \text { - Laplasov operator } \\
u, v & - \text { shifts in } x \text { and } y \text { direction respectively } \\
v=\frac{\partial u}{\partial x}+\frac{\partial v}{\partial y} & - \text { volume dilatation } \\
\varepsilon=\frac{\mu}{\lambda+\mu} & \begin{array}{c}
\text { - constant defined using familiar } \\
\text { Laméovih parameters }
\end{array}
\end{array}
$$

With the quite simple mathematical operations system (1) can be transformed into the following form:

$\Delta v=0$ 
Mathieu's approach to the 2D elasticity problem starts with the careful selection of two ordinary Fourier series for $v$ (4) with infinite unknown coefficients, taking into account the symmetry or anti-symmetry of the stresses with respect to the $x$ and $y$ directions.

$v=v_{1}+v_{2}$

The following step presents the introduction of the function $F$ $\left(F_{1}+F_{2}\right)$, from the conditions that the equation is fulfilled:

$$
\Delta F=-\frac{1}{\varepsilon} v \Rightarrow \quad \begin{aligned}
\Delta F_{2} & =-\frac{1}{\varepsilon} v_{2} \\
\Delta F_{2} & =-\frac{1}{\varepsilon} v_{2}
\end{aligned}
$$

Finally, when displacements $u$ and $v$ are determined

$u=\frac{d F}{d x}+\alpha \int v_{1} d x$

$v=\frac{d F}{d y}+\alpha \int v_{2} d y$

where:

$\alpha=\frac{(\lambda+2 \mu)}{\mu}-$ constant expressed with Laméo parameters

normal stresses $N_{1}$ and $N_{2}$ are defined along the axes $x$ and $y$, as well as the in-plane shear stress $T_{3}$

$$
\begin{aligned}
& N_{1}=\lambda v+2 \mu \alpha v_{1}+2 \mu \frac{d^{2} F}{d x^{2}} \\
& N_{2}=\lambda v+2 \mu \alpha v_{2}+2 \mu \frac{d^{2} F}{d y^{2}} \\
& T_{3}=\mu\left[2 \frac{d^{2} F}{d x d y}+\alpha \int \frac{d v_{1}}{d y} d x+\alpha \int \frac{d v_{2}}{d x} d y\right]
\end{aligned}
$$

As it is pointed above, Mathieu's solution for the basic case DEA has already been presented $[3,4,5]$. In this paper, special attention is paid to the second load case (DEB), with all necessary explanations and comments.

\subsection{Exact stress function for the fundamental load case (DEB)}

Obviously, DEB case is not in self-equilibrium and involves rigid-body translation.

$$
\text { DEB - boundary conditions: }
$$

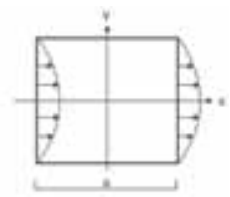

external load:

$f(y)=A_{0}+\sum_{n} A_{n} \cos n y$

\section{Introduction of the series}

In this case, series odd in $x$ but even in $y$ must be chosen for the dilatation functions.

$v_{1}=D x+\sum_{n} B_{n} e(n x) \cos n y, n=\frac{2 q \pi}{b} \quad q=1,2,3, \ldots$

$v_{2}=\sum_{m} \beta_{m} E(m y) \sin m x, m=\frac{p \pi}{a} \quad p=1,3,5, \ldots$

Therefore, the expressions for $F_{1}$ and $F_{2}$ are:

$F_{1}=-\frac{D}{6 \varepsilon} x^{3}-\frac{1}{2 \varepsilon} \sum_{n} \frac{1}{n} B_{n} x E(n x) \cos n y+\sum_{n} H_{n} e(n x) \cos n y$

$F_{2}=-\frac{1}{2 \varepsilon} \sum_{m} \frac{1}{m} \beta_{m} y e(m y) \sin m x+\sum_{m} G_{m} E(m y) \sin m x$

In the aim of more efficient writing of very long expressions, certain abbreviations are introduced $(E()=\cosh ()$ and $\mathrm{e}()=$ $\sinh ())$.

\section{Boundary conditions}

From the boundary condition of $T_{3}=0$ on $x=a / 2$, the following expression for $H_{n}$ is obtained:

$H_{n}=B_{n}\left[-\frac{1}{2 n^{2}}+\frac{a}{4 n \varepsilon} \frac{e\left(\frac{1}{2} n a\right)}{E\left(\frac{1}{2} n a\right)}\right]$

Components containing $\cos \frac{1}{2}$ ma can be eliminated with the proper selection of the parameter $m=p \pi / a, p=1,3,5, \ldots(11 b)$. Similarly, from the boundary condition of $T_{3}=0$ on $y=b / 2$, and noticing that $\left(\sin \frac{1}{2} n b=0\right)$ for the values $n=2 q \pi / b, q=1,2,3$, ... the expression for $G_{m}$ follows:

$G_{m}=\beta_{m}\left[-\frac{1}{2 m^{2}}+\frac{b}{4 m \varepsilon} \frac{E\left(\frac{1}{2} m b\right)}{e\left(\frac{1}{2} m b\right)}\right]$

The second group of the boundary conditions is used to produce infinite system for constants $B_{n}$ and $\beta_{m}$.. Therefore, considering equations (13), the boundary condition of $N_{1}=f(y)$ on $x=a / 2$ yields:

$$
\begin{aligned}
& \frac{(\lambda+2 \mu) D a-2 A_{0}}{2(\lambda+\mu)}+\sum_{n}\left[B_{n}\left(e\left(\frac{1}{2} n a\right)-\frac{n a}{2} \frac{1}{E\left(\frac{1}{2} n a\right)}\right)-\frac{A_{n}}{(\lambda+\mu)}\right] \cos n y \\
& +\sum_{m} \beta_{m}\left[\left(1-\frac{m b}{2} \frac{E\left(\frac{1}{2} m b\right)}{e\left(\frac{1}{2} m b\right)}\right) E(m y)+m y e(m y)\right] \sin \frac{1}{2} m a=0
\end{aligned}
$$

Similarly, the fourth condition of $N_{2}=0$ on $y=b / 2$ results in:

$$
\begin{aligned}
& \frac{\lambda D x}{(\lambda+\mu)}+\sum_{n} B_{n}\left[\left(1-\frac{n a}{2} \frac{e\left(\frac{1}{2} n a\right)}{E\left(\frac{1}{2} n a\right)}\right) e(n x)+n x E(n x)\right] \cos \frac{1}{2} n b \\
& +\sum_{m} \beta_{m}\left(E\left(\frac{1}{2} m b\right)+\frac{m b}{2} \frac{1}{e\left(\frac{1}{2} m b\right)}\right) \sin m x=0
\end{aligned}
$$

Coefficients $B_{n^{\prime}} \beta_{m}$ and $B_{0^{\prime}} b_{0}$

Multiplying by $d y$ and integrating between $\pm b / 2$, equation (14a) reduces to its first term:

$$
D=\frac{2 A_{0}}{(\lambda+2 \mu) a}
$$




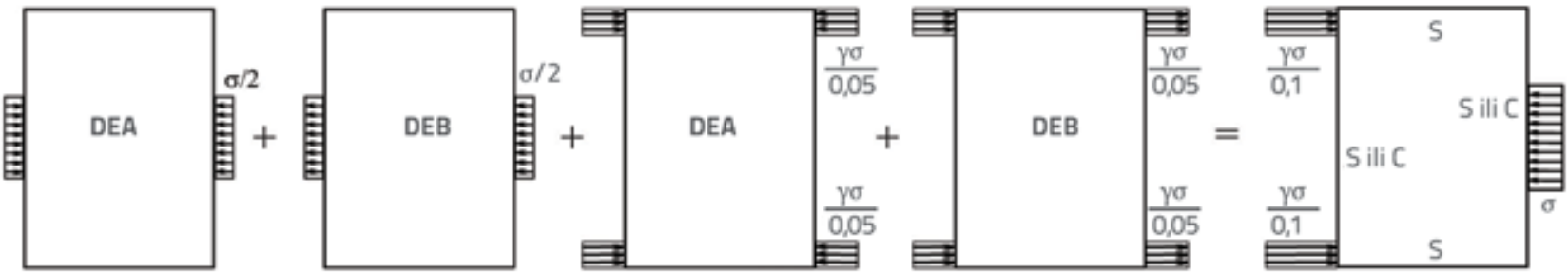

Figure 5. Creating of model 1 by superposition of two fundamental load cases DEA and DEB

On the other hand, second group of coefficients are obtained by multiplying equations (14a) and (14b) by cosnydy and $\sin m x d x$ respectively and integrating between $\pm b / 2$ and $\pm a / 2$ respectively:

$$
\begin{aligned}
& B_{n}=\frac{A_{n}}{(\lambda+\mu) \sigma\left(\frac{1}{2} n a\right)}-\frac{8 n^{2} \cos \frac{1}{2} n b}{b \sigma\left(\frac{1}{2} n a\right)} \sum_{m} \beta_{m} \frac{m e\left(\frac{1}{2} m b\right) \sin \frac{1}{2} m a}{\left(m^{2}+n^{2}\right)^{2}} \\
& \beta_{m}=-\frac{4 \lambda D \sin \frac{1}{2} m a}{(\lambda+\mu) a m^{2} \tau\left(\frac{1}{2} m b\right)}-\frac{8 m^{2} \sin \frac{1}{2} m a}{a \tau\left(\frac{1}{2} m b\right)} \sum_{n} B_{n} \frac{n E\left(\frac{1}{2} n a\right) \cos \frac{1}{2} n b}{\left(m^{2}+n^{2}\right)^{2}}
\end{aligned}
$$

At the end, final expression for coefficients $\beta_{\mathrm{m}}$ and $B_{n}(17)$ are obtained by using recursive iteration. Namely, Mathieu proposed the way to solve the system by so-called "reduction" method in which infinite sets of infinite series are recursively "looped" into one another to solve "exactly" infinite system of equations.

$$
\begin{aligned}
B_{q}= & \frac{A_{q}}{(\lambda+\mu) \sigma(q \pi \varphi)}+\frac{16 \varphi^{4} q^{2}(-1)^{q}}{(\lambda+\mu) \pi^{2} \sigma(q \pi \varphi)} \sum_{q^{\prime}} q^{\prime} A_{q^{\prime}}(-1)^{q^{\prime}} \chi\left(q^{\prime} \pi \varphi\right) \\
& \times\left\{\Lambda_{1}\left(q, q^{\prime}\right)+\left(16 \varphi^{4} / \pi^{2}\right) \Lambda_{3}\left(q, q^{\prime}\right)+\left(16 \varphi^{4} / \pi^{2}\right)^{2} \Lambda_{5}\left(q, q^{\prime}\right)+\cdots\right\} \\
& +\frac{8 \lambda \varphi^{3} q^{2}(-1)^{q} A_{0}}{(\lambda+\mu)(\lambda+2 \mu) \pi^{3} \sigma(q \pi \varphi)} \sum_{p} \frac{\Psi(p \pi / 2 \varphi)}{(p / 2)} \\
& \times\left\{\Lambda_{0}(p, q)+\left(16 \varphi^{4} / \pi^{2}\right) \Lambda_{2}(p, q)+\left(16 \varphi^{4} / \pi^{2}\right)^{2} \Lambda_{4}(p, q)+\cdots\right\} \\
\beta_{p}= & -\frac{2 \lambda A_{0}(-1)^{(p-1) / 2}}{(\lambda+\mu)(\lambda+2 \mu)(p / 2)^{2} \pi^{2} \tau(p \pi / 2 \varphi)}-\frac{32 \lambda \varphi^{4}(p / 2)^{2} A_{0}(-1)^{(p-1) / 2}}{(\lambda+\mu)(\lambda+2 \mu) \pi^{2} \tau(p \pi / 2 \varphi)} \\
& \times \sum_{p^{\prime}} \frac{\Psi\left(p^{\prime} \pi / 2 \varphi\right)}{\left(p^{\prime} / 2\right)}\left\{Z_{0}\left(p, p^{\prime}\right)+\left(16 \varphi^{4} / \pi^{2}\right) Z_{2}\left(p, p^{\prime}\right)+\left(16 \varphi^{4} / \pi^{2}\right)^{2} Z_{4}\left(p, p^{\prime}\right)+\cdots\right\} \\
& -\frac{4 \varphi(p / 2)^{2}(-1)^{(p-1) / 2}}{(\lambda+\mu) \pi \tau(p \pi / 2 \varphi)} \sum_{q} q A_{q}(-1)^{q} \chi(q \pi \varphi)
\end{aligned}
$$

In the aim of making the equations simplier, the following abbreviations are introduced:

$$
\sigma(x)=e(x)-x / E(x), \quad \chi(x)=E(x) / \sigma(x)
$$

while $\Lambda$ and $\mathrm{Z}$ functions are in non-dimensional form:

$$
\begin{aligned}
& \Lambda_{0}(p, q)=\frac{1}{\left((p / 2)^{2}+\varphi^{2} q^{2}\right)^{2}} \\
& \Lambda_{1}\left(q, q^{\prime}\right)=\sum_{p} \frac{(p / 2)^{3} \Psi(p \pi / 2 \varphi)}{\left((p / 2)^{2}+\varphi^{2} q^{\prime 2}\right)^{2}} \Lambda_{0}(p, q) \\
& \Lambda_{2}(p, q)=\sum_{q^{\prime}} \frac{q^{\prime 3} \chi\left(q^{\prime} \pi \varphi\right)}{\left((p / 2)^{2}+\varphi^{2} q^{\prime 2}\right)^{2}} \Lambda_{1}\left(q, q^{\prime}\right) \\
& \Lambda_{3}\left(q, q^{\prime}\right)=\sum_{p} \frac{(p / 2)^{3} \Psi(p \pi / 2 \varphi)}{\left((p / 2)^{2}+\varphi^{2} q^{\prime 2}\right)^{2}} \Lambda_{2}(p, q) \\
& \Lambda_{4}(p, q)=\sum_{q^{\prime}} \frac{q^{\prime 3} \chi\left(q^{\prime} \pi \varphi\right)}{\left((p / 2)^{2}+\varphi^{2} q^{\prime 2}\right)^{2}} \Lambda_{3}\left(q, q^{\prime}\right) \\
& Z_{0}\left(p, p^{\prime}\right)=\sum_{q} \frac{q^{3} \chi(q \pi \varphi)}{\left(\left(p^{\prime} / 2\right)^{2}+\varphi^{2} q^{2}\right)^{2}} \Lambda_{0}(p, q)
\end{aligned}
$$

$$
\begin{aligned}
& Z_{2}\left(p, p^{\prime}\right)=\sum_{q} \frac{q^{3} \chi(q \pi \varphi)}{\left(\left(p^{\prime} / 2\right)^{2}+\varphi^{2} q^{2}\right)^{2}} \Lambda_{2}(p, q) \\
& Z_{4}\left(p, p^{\prime}\right)=\sum_{q} \frac{q^{3} \chi(q \pi \varphi)}{\left(\left(p^{\prime} / 2\right)^{2}+\varphi^{2} q^{2}\right)^{2}} \Lambda_{4}(p, q)
\end{aligned}
$$

\section{Stresses}

Finally, expressions for the exact stress functions for the plate under load case (DEB) are:

$$
\begin{aligned}
N_{1}= & \frac{2 A_{0}}{a} x+(\lambda+\mu) \sum_{n} B_{n}\left[\left(1+\frac{n a}{2} \frac{e\left(\frac{1}{2} n a\right)}{E\left(\frac{1}{2} n a\right)}\right) e(n x)-n x E(n x)\right] \cos n y \\
& +(\lambda+\mu) \sum_{m} \beta_{m}\left[\left(1-\frac{m b}{2} \frac{E\left(\frac{1}{2} m b\right)}{e\left(\frac{1}{2} m b\right)}\right) E(m y)+m y e(m y)\right] \sin m x \\
N_{2}= & \frac{2 \lambda A_{0}}{a(\lambda+2 \mu)} x+(\lambda+\mu) \sum_{n} B_{n}\left[\left(1-\frac{n a}{2} \frac{e\left(\frac{1}{2} n a\right)}{E\left(\frac{1}{2} n a\right)}\right) e(n x)+n x E(n x)\right] \cos n y \\
& +(\lambda+\mu) \sum_{m} \beta_{m}\left[\left(1+\frac{m b}{2} \frac{E\left(\frac{1}{2} m b\right)}{e\left(\frac{1}{2} m b\right)} E(m y)-m y e(m y)\right] \sin m x\right. \\
T_{3}= & (\lambda+\mu) \sum_{n} B_{n}\left(-\frac{n a}{2} \frac{e\left(\frac{1}{2} n a\right)}{E\left(\frac{1}{2} n a\right)} E(n x)+n x e(n x)\right) \sin n y \\
& +(\lambda+\mu) \sum_{m} \beta_{m}\left(\frac{m b}{2} \frac{E\left(\frac{1}{2} m b\right)}{e\left(\frac{1}{2} m b\right)} e(m y)-m y E(m y)\right) \cos m x
\end{aligned}
$$

In Table 1, stress distributions for the case of patch loading defined by the model 1 are presented. These functions are obtained by analytical approach, on the one side, and on the other, by ANSYS software based on the finite element method. For the one selected case $(\phi=1$ and $\gamma=0,1$ ), in order to obtain exact stress function, superposition of four different load types is performed (figure 5 ) and stress distributions, calculated by MATHEMATICA software, are presented in Table 1. In order to control results, several stress values, chosen from analytical solution, are used during chart drawing in ANSYS. That way, by overlapping two diagrams in the last column, it is possible to notice extremely good contour matching.

\subsection{Analytical approach to plate buckling}

The problem of the elastic stability of rectangular plates with different boundary conditions is investigated using the Ritz energy technique. The strain energy due to bending of the plate is defined in the traditional way. On the other hand, the exact stress distribution of Mathieu's theory of elasticity is introduced through the potential energy of the plate associated with the work done by external loads. By adopting the exact stresses within a plate under patch loading and using the double Fourier series to represent any possible buckled profile, the buckling loads can be obtained in a very accurate way. Analytical 
Table 1. Stresses distribution within plate obtained by analytical approach and by software (ANSYS) based on the finite element method

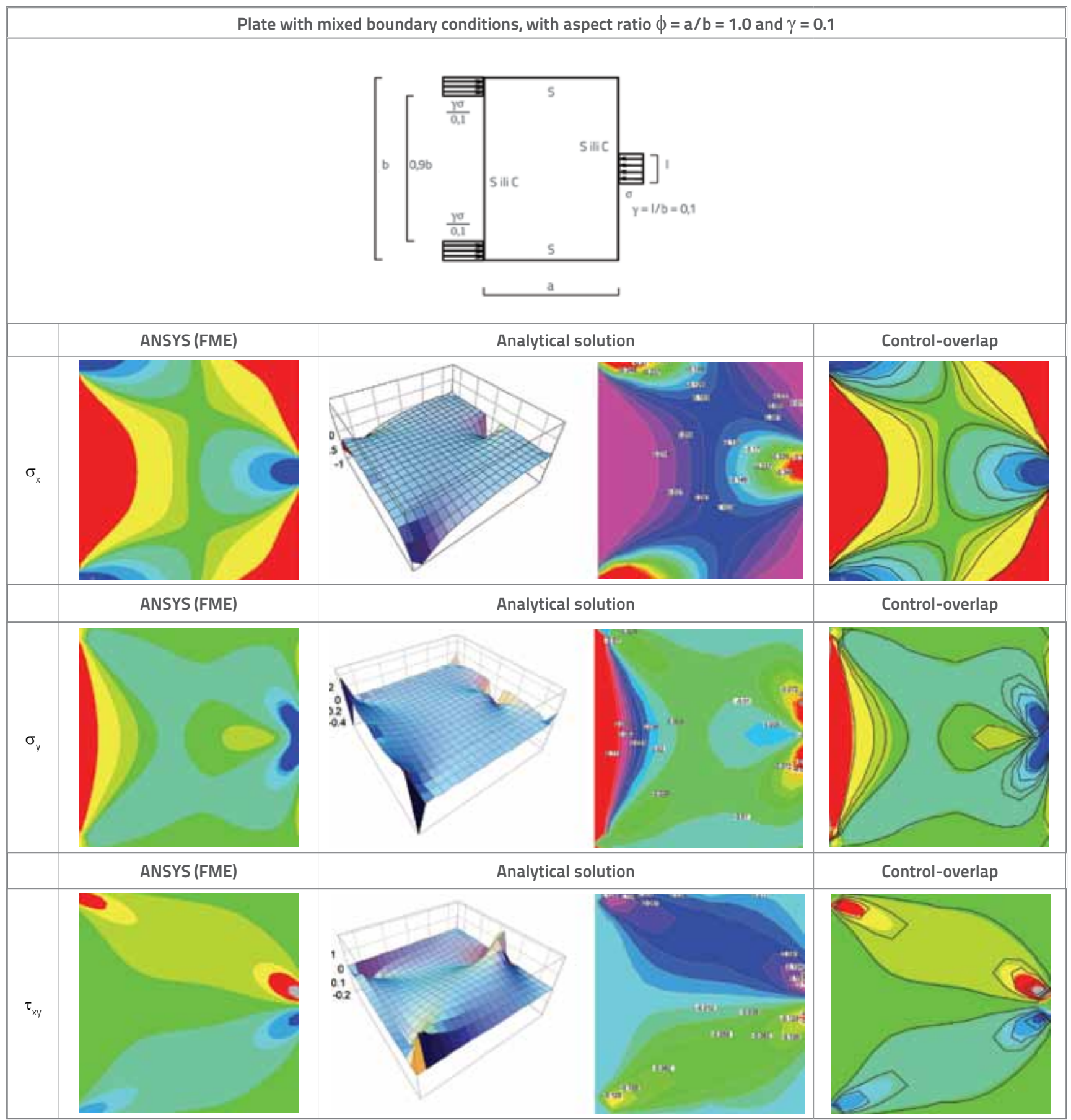

approach to plate buckling under patch loading is presented in the examples of the rectangular simply supported plates (SSSS) as well as in plates with two edges simply supported and other two clamped (CSCS). In order to verify the results from analytical method, the finite-element method (ANSYS) is used to produce buckling coefficients for the considered problem. Presently available literature has no records on analytical solutions dealing with the subject.

\subsubsection{The adopted deflection series}

In order to guarantee the accuracy, the double Fourier series are used to represent buckled profiles of the two chosen types of plates (22-23). These series satisfy all boundary conditions, term by term, and, as it has been previously shown [4-5], are capable of representing any possible buckled profiles for very wide range of aspect ratios and load cases. 


\section{Case 1}

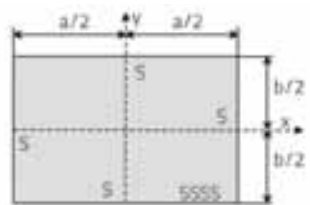

edges $x= \pm a / 2$ simply supported (S) edges $y= \pm b / 2$ simply supported $(S)$

Figure 6. Simply supported plate SSSS

$w=\sum_{m=1}^{s} \sum_{n=1}^{s} W_{m n} \sin \frac{m \pi}{a}\left(x+\frac{a}{2}\right) \sin \frac{n \pi}{b}\left(y+\frac{b}{2}\right)$

\section{Case 2}

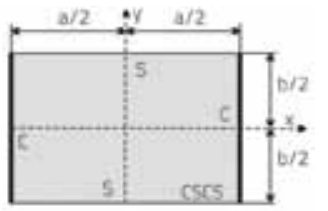

edges $x= \pm a / 2$ clamped (C)

edges $y= \pm b / 2$ simply supported (S)

Figure 7. Plate with mixed boundary conditions CSCS

$w=\sum_{m=1}^{s} \sum_{n=1}^{s} W_{m n}\left(\cos \frac{(m-1) \pi}{a}\left(x+\frac{a}{2}\right)-\cos \frac{(m+1) \pi}{a}\left(x+\frac{a}{2}\right)\right) \sin \frac{n \pi}{b}\left(y+\frac{b}{2}\right)$

\subsubsection{Strain energy due to bending}

During the evaluation of the total potential energy of the plate, the first step is defining the strain energy due to plate bending in the traditional way

$U=\frac{1}{2} D \int_{-a / 2}^{a / 2} \int_{-b / 2}^{b / 2}\left[\left(\frac{\partial^{2} w}{\partial x^{2}}+\frac{\partial^{2} w}{\partial y^{2}}\right)^{2}-2(1-v)\left[\frac{\partial^{2} w}{\partial x^{2}} \frac{\partial^{2} w}{\partial y^{2}}-\left(\frac{\partial^{2} w}{\partial x \partial y}\right)^{2}\right]\right] d x d y$

where $D$ is flexural rigidity of the plate.

The part of the potential energy of the plate associated with the work done by external loads is presented by the expression (25). In this expression, the stresses within the plate $N_{1}, N_{2}$ and $T_{3}$ are given by equations (21) that represent solutions of the Mathieu's exact approach:

$V=-\frac{t}{2} \int_{-a / 2}^{a / 2} \int_{-b / 2}^{b / 2}\left[N_{1}\left(\frac{\partial w}{\partial x}\right)^{2}+N_{2}\left(\frac{\partial w}{\partial y}\right)^{2}+2 T_{3} \frac{\partial w}{\partial x} \frac{\partial w}{\partial y}\right] d x d y$
Introducing the exact stress functions makes the expression for the work done by external forces more complex. It presents the basic difference in relation to the all previous analyses of the stability of plates which are not simply supported along all edges.

\subsubsection{Formulation of eigenvalue problem}

Finally, after the definition of the strain energy of the plate bending $U$, and of the value which responds to the work done by external forces $V$, the total potential energy of the system can be written in form:

$\Pi=U+V$

From the minimum potential energy principle, the condition (27) is given by

$\frac{\partial \Pi}{\partial W_{m n}}=\frac{\partial U}{\partial W_{m n}}+\frac{\partial V}{\partial W_{m n}}$

which basically represents linear system of $m \cdot n$ homogenous equations per unknown coefficients $W_{m n}$. The existence of nontrivial solution, expressed through condition that the determinant of the system is equal to zero, leads to the solution of the classical eigenvalue problem. In its scope, the lowest value has the only practical importance, which presents the requested critical load. Surely, the usage of the corresponding software (MATHEMATICA) was necessary in the solving process because of the complexity of the analytical procedure. The complexity directly depends on the adopted number of terms of the stress functions, as well as of number of terms of the deflection functions.

\section{Numerical examples and results}

For the case of patch-loading analyzed by model 1, all results for buckling load coefficients for two type of plates with different boundary conditions (SSSS and CSCS), calculated for plate aspect ratios between $\phi=0.3-1$ and different load
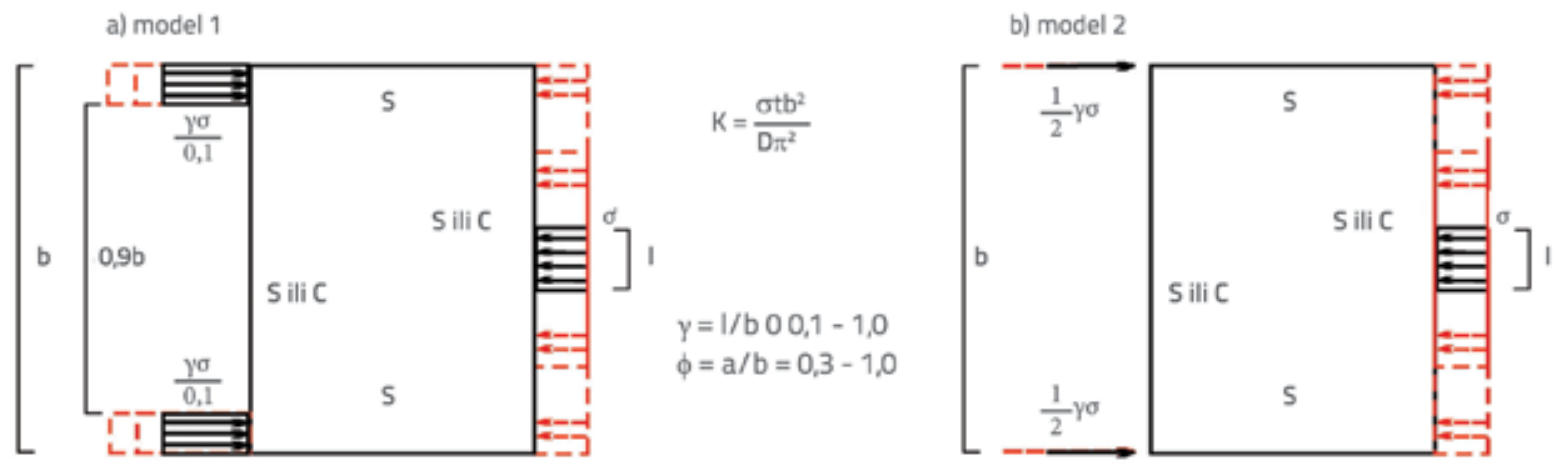

Notation: $\mathrm{K}$ - buckling coefficients; $\mathrm{t}$ - plate thickness; $\mathrm{D}$ - flexural rigidity of the plate $D=E t^{3} / 12\left(1-n^{2}\right)$

Figure 8. Numerical examples 
distributions $\gamma=0.1-1$, are presented in Tables 2 and 3. On the other hand, critical loads obtained by model 2 are presented in the chart form (Figure 9.a and 9.b) to enable easy comparison between results of two patch loading models (Figure 8.).

In these tables for the model 1, there are not only buckling coefficients obtained by analytical approach, but also there are, as some kind of "experimental" values, the results of finite element method (ANSYS).

It is important to point out that when it comes to analytical solutions in the form of infinite series, convergence control is required. Namely, from the practical reasons it was necessary to include some limits regarding number of series terms for stress as well as for deflection functions. Because of that limitation, every proposed analytical approach to critical load determination required thorough convergence control. From the stress function point of view, for the load types DEA and $D E B$, accuracy of the solution is achieved with 40 and more terms. In the case of the deflection function, sometimes it is desirable the presence of more number of terms in dependence on boundary conditions and types of the load. For initial patch loading models with two different types of boundary conditions (SSSS and CSCS) analyzed in this paper, deflection functions with 20 terms (22-23) were absolutely capable to describe deformed shape for any plate $\phi$ or load $\gamma$ aspect ratio.

Certainly, we are aware of the fact we get the solution little bit higher than exact one, by limiting the numbers of terms. However, analyzing results from Tables 2 and 3, obtained

Table 2. Buckling coefficients for model 1 in the case of plate SSSS $(\phi=0.3-1, \gamma=0.1-1)$

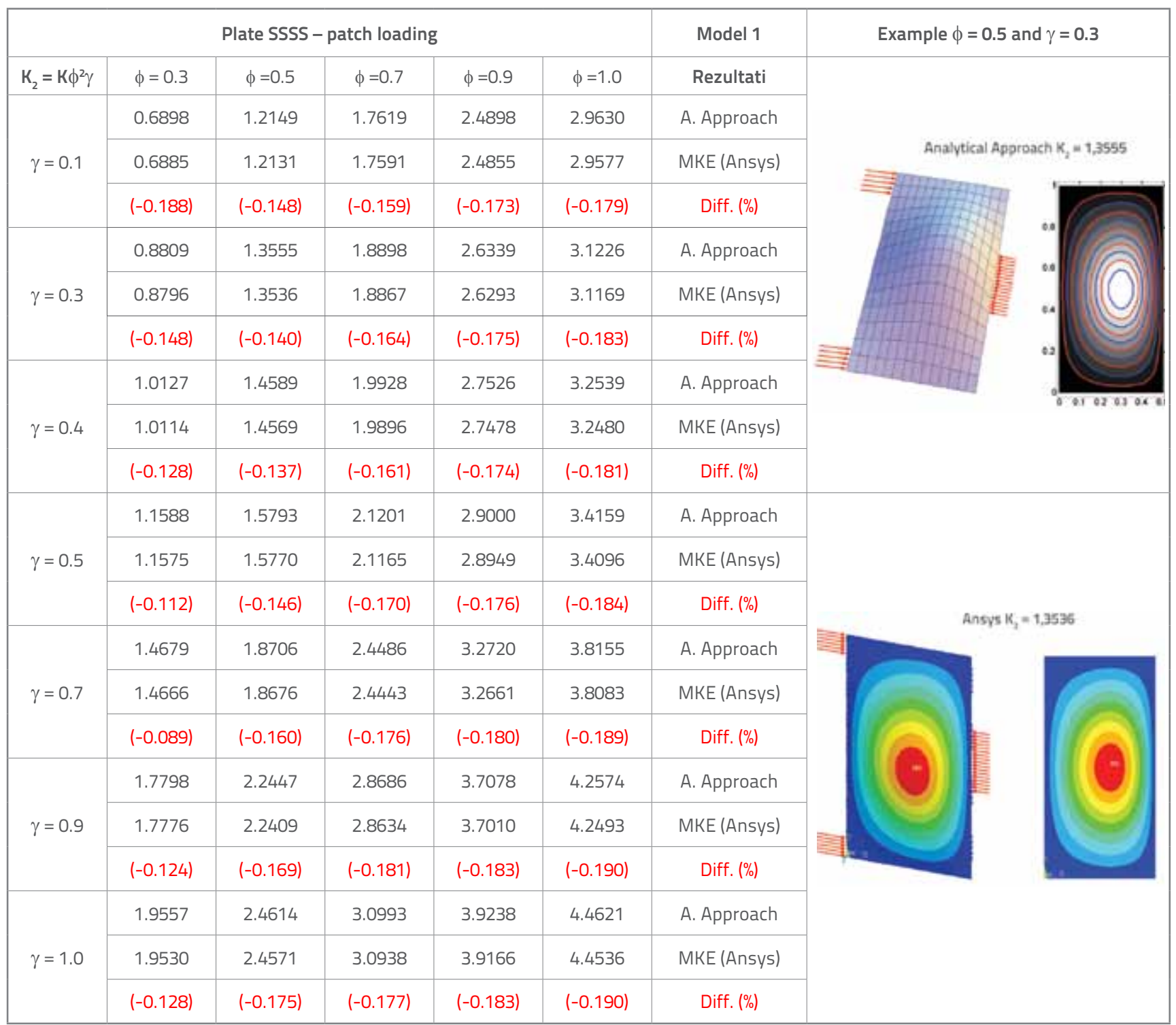


Table 3. Buckling coefficients for model 1 in the case of plate $\operatorname{CSCS}(\phi=0.3-1, \gamma=0.1-1)$

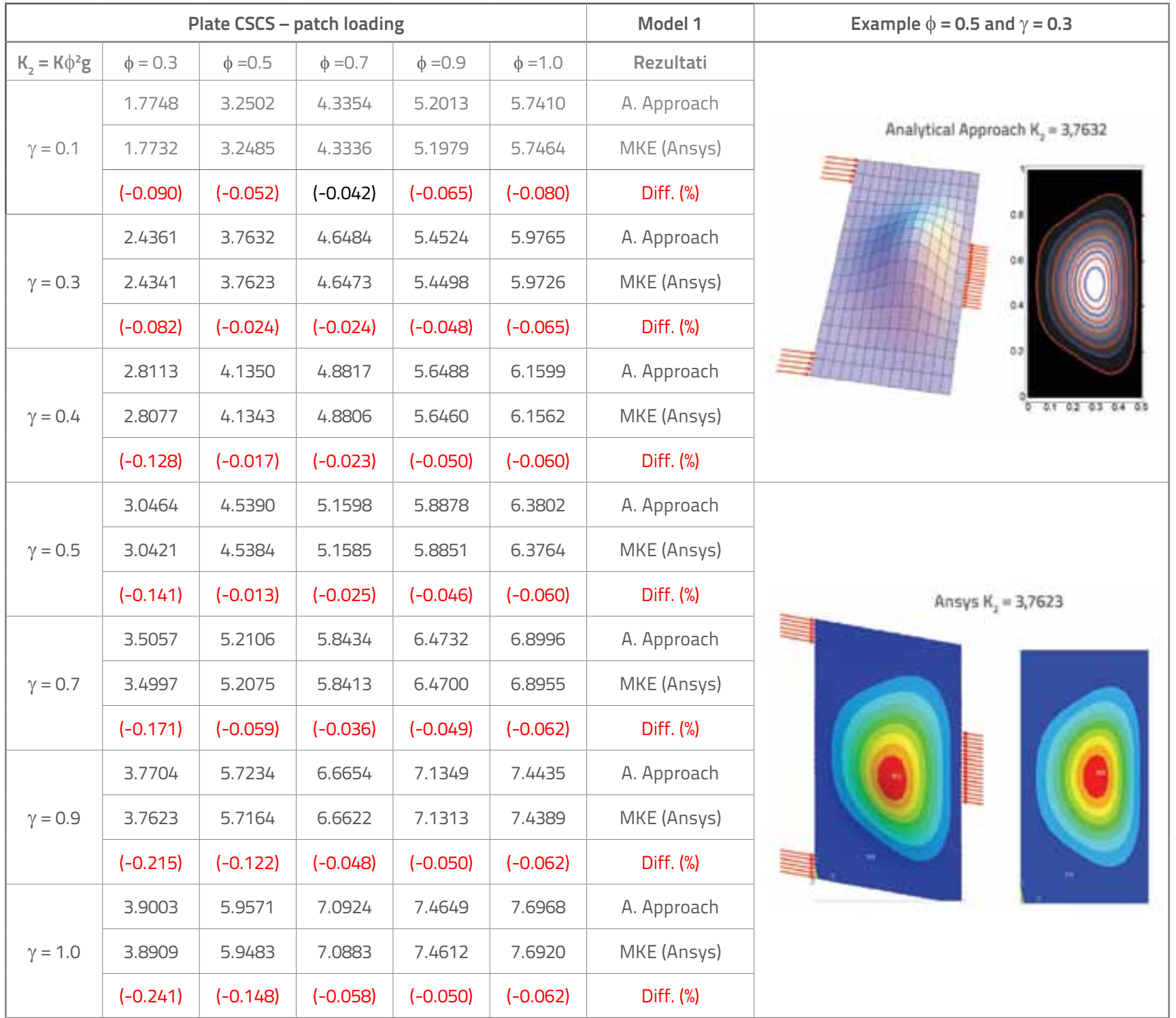

with 20 terms of deflection functions, it is obvious that by increasing number of terms we would not improve accuracy significantly but on the other hand it would increase the complexity of analytical approach.

\section{Analysis of the results of calculations}

With the detailed analysis of the presented results for model 1 (Tables 2 and 3), it is very easy to notice very good behavior of analytical solution for both types of boundary conditions in the complete considered ranges of the plate $(\phi=0.3-1)$ and load $(\gamma=0.1-1)$ aspect ratios. Tables 2 and 3, which present values of buckling coefficients of two types of plates (SSSS, CSCS) under patch loading defined with model 1, refer to the maximal discrepancy of $0.25 \%$ (CSCS $\phi=0.3$ and $\gamma=1$ ) in relation to the results evaluated by the application of the finite element method.
It is important to point out that for the problems regarding stability of the plates, buckling coefficients obtained by finite element method are below exact values, as a result of limited number of terms in interpolation functions. Knowing that, small existing discrepancy between presented results confirms accuracy of the analytical approach.

Results obtained with model 2 were subjected to the same type of control. Comparison with finite element method solutions (ANSYS) confirms high level of concordance for all load and plate types (maximal discrepancy for the simply supported plate SSSS is $0.3 \%$, for the case of $\phi=0.1$ and $\gamma=1$; maximal discrepancy for the clamped plate CSCS is $0.95 \%$ for the same case of $\phi=0.1$ and $\gamma=1$ ). The reason why results for model 2 are presented in the chart form instead of table form is because of a slight deviation from model 1 and better models comparison (Figure 9). 
Plate SSSS

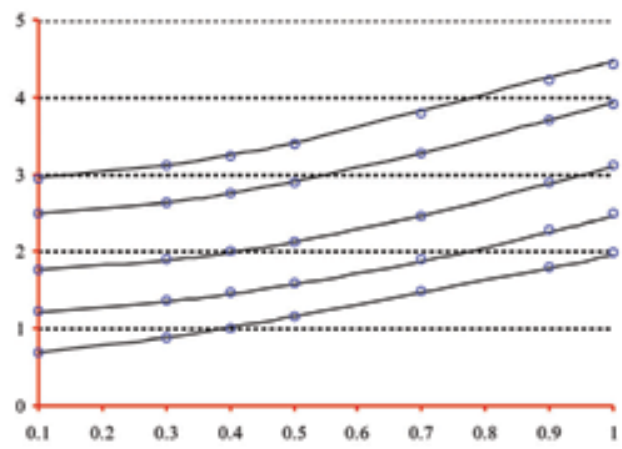

Plate CSCS

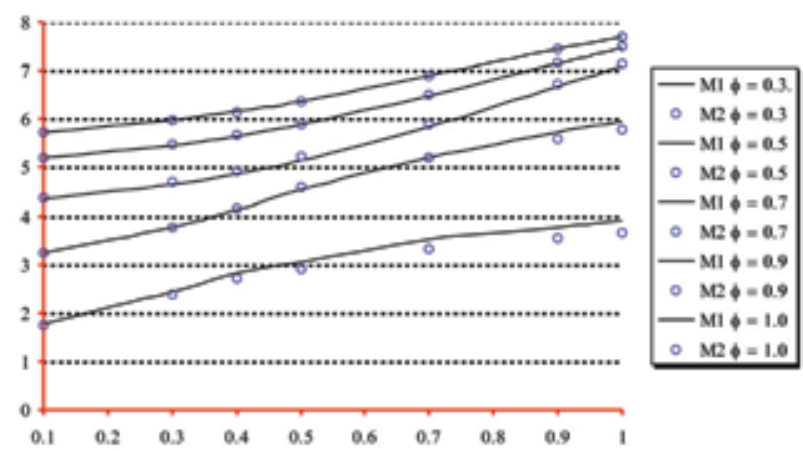

Figure 9. Comparative analysis for buckling coefficient obtained with: model 1 (M1) and model 2 (M2)

From the chart, it is obvious that in the case of simply supported plate (Figure 9a) maximal discrepancy between two models is in the range $-0.9 \%(\gamma=0.1)$ and $1.5 \%(\gamma=1)$ for aspect ratio $\phi=0.3$. In all other cases regarding plate SSSS discrepancy in buckling load for two models are within $1 \%$. In the case of plate with two clamped edges CSCS, some discrepancy was expected, especially for the category of wide strips ( $\phi=0.3$ and $\phi=0.5$ ). Figure 9.b point out that results for model 2 are slightly below corresponding values calculated for the model 1 (up to $6 \%$ for $\phi=0.3$ and $\gamma=1$ ). However, for nearly square plates, in all load range, discrepancy is within $0.1 \%$. As

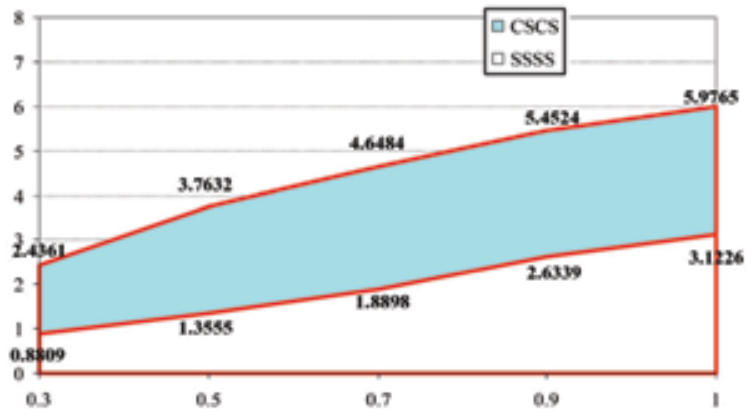

Figure 10. Buckling load for plates SSSS i CSCS obtained with model 1 a final conclusion we can point out that two models have very similar behavior under patch loading which results in very similar, almost identical buckling coefficients.

Since in this paper the behavior of plates with simply supported and clamped edges is investigated, it was considered interesting to analyze increase in buckling capacity due to different boundary conditions (SSSS and CSCS). For the load case $\gamma=0.3$ (Figure 10.), the difference between values of critical load for simply supported and clamped plates is, especially for category of wide strips, up to 2.8 times (for plate SSSS with aspect ratio $\phi=$ 0.3 coefficient is $K_{2}=0.8809$ while for plate CSCS is $K_{2}=2.4361$ ). For the full load range increase is in-between 1.7 and 2.8 times.

\section{Conclusion}

At the end, the main conclusion can be that obtained exact stress functions, as well as adopted deflection functions, for the two initial mathematical models, are capable to describe the behavior of the plates under patch loading and produce very accurate solutions. Now it is possible to go a step further and build new, more advanced models, by introducing shear stresses along the shorter plate edges and/or shear effects on the flange-web junction. Until now, such effect has never been discussed analytically.

\section{REFERENCES}

[1] Mathieu, E.: Theorie de l'elasticite des corps solides, Seconde partie. GauthierVillars, Paris.1890.

[2] Baker, G., Pavlović, M.N. \& Tahan, N.: An exact solution to the two-dimensional elasticity problem with rectangular boundaries under arbitrary edge forces, Phil. Trans. R. Soc. London, A 393, pp. 307-336, 1993.

[3] Liu, Y. G.: Buckling of Plates under Non-Uniform Stresses, with Particular Emphasis on Shear, Ph. D Thesis, Imperial College, London, 2006

[4] Mijušković, O.: Analiza stabilnosti pravougaonih ploča koriščenjem tačne funkcije napona, Doktorska disertacija, Građevinski fakultet, Beograd 2008.

[5] Mijušković, O., Ćorić, B.: Analytical Procesure for Determining Critical Load of Plates with Variable Boundary Conditions, original scientific paper, Gradevinar, Journal of the Croatian Association of Civil Engineers, Vol. 64 (3), pp. 185-194, Zagreb, 2012.

[6] Liu, Y.G., Pavlović, M.N.: Elastic Stability of Flat Rectangular Plates under Patch Compression, International Journal of Mechanical Sciences, 49 (8), pp. 970-982, 2007.

[7] Liu, Y.G., Pavlović, M.N.: A Generalized Analytical Approach to the Buckling of Simply-supported Rectangular Plates under Arbitrary Loads, Engineering Structures, 30 (5), pp. 1346-1359, 2008 